\title{
International Perspectives about COVID-19, Digital Labour and Gender Work Pattern: A Collective Interview
}

\section{Annette von Alemann, Julia Gruhlich, Ilona Horwath, Lena Weber}

\author{
Alemann, Annette von, Gruhlich, Julia, Horwath, Ilona, Weber, Lena. 2020. International \\ Perspectives about COVID-19, Digital Labour and Gender Work Pattern: A Collective Inter- \\ view. Gender a výzkum / Gender and Research 21 (2): 86-102, http://dx.doi.org/10.13060/ \\ gav.2020.014.
}

In this special issue, we want to capture different country perspectives on the connection between the digitalisation of work and gender relations. As a result of the COVID-19 pandemic, the world has suddenly found itself in an exceptional situation that had not been foreseen in our editorial project but proved to be relevant for gendered work patterns and digitalisation. Digital systems and devices have seemed to offer the best solutions to the situation of the pandemic and the subsequent lockdowns all over the world. It has become apparent, however, that not everyone has equal access to the internet and technical knowledge of computing, and that women and men have been affected in very different ways by the COVID-19 crisis in their (digital or not) work environments. To find out more about the situation all over the world, we asked some gender researchers and social and technical scientists from South Africa, Canada, the Czech Republic, Great Britain, Belgium, Finland, and Austria a few questions via e-mail about their personal impressions from the COVID-19 pandemic and their own working situation. What we present here is the innovative format of an 'artificial collective interview': the responses have been shortened and compiled, but not reformulated. However, the questions have been modified to give the impression of a face-to-face group interview, though the interaction actually took the form of one-to-one email communication. The answers were collected during the summer period in AugustSeptember 2020. The interviewees were chosen because their work focused on 
gender and digitalisation even before the COVID-19 crisis and/or because they did research, published, or blogged about the events during the pandemic, or because they have been perceived as experts in areas that have changed rapidly.

The interviewees are:

Deevia Bhana, DSI/NRF South African Research Chair (SARChI): Gender and Childhood Sexuality, School of Education, University of KwaZulu-Natal, South Africa.

Mark Gatto, Graduate Research Associate (Supporting Equality, Diversity \& Inclusion projects) at the Faculty of Business and Law, Northumbria University, Newcastle. Together with Amal Abdellatif he wrote an auto-ethnography about their academic work situation during the pandemic. His research explores the influence of masculinity on working parents' discourses and decisions at work and at home.

Jeff Hearn, Senior Professor in Gender Studies, Örebro University, Sweden; Professor of Sociology, University of Huddersfield, UK; Professor Emeritus, Hanken School of Economics, Finland; Professor Extraordinarius, University of South Africa. $\mathrm{He}$ is working on several relevant issues, including age and ageism in organisations and digital work and violation.

Nicole Horáková Hirschlerová, Assistant Professor in the Department of Sociology, University of Ostrava, Czech Republic.

Gabriele Kotsis, President of the Association for Computing Machinery (ACM), Full Professor in Computer Science and Head of the Department of Telecommunication and the division of Cooperative Information Systems Kepler University Linz, Austria.

Chia Longman, Associate Professor in Gender Studies, Director of the Centre for Research on Culture and Gender and the Inter University Master Programme in Gender and Diversity, Ghent University, Belgium. She opened a discussion on Facebook about the 'home office' mode of work and virtual teaching.

Tamara Shefer, Professor and Chairperson, Women's and Gender Studies Department Faculty of Arts, University of the Western Cape, Cape Town, South Africa. Currently she is involved in a student project on the gendered impact of COVID-19.

Anne Wagner, PhD, School of Social Work, Faculty of Education and Professional Studies, Nipissing University, Canada. Her research focuses on feminist researchers in neoliberal universities. She teaches in the Faculty of Education and Professional Studies, which is why she was interviewed about the teaching situation. 


\section{Editors: How did you experience the COVID-19 pandemic in your country and how has the situation affected your work?}

Nicole Horáková: The COVID-19 pandemic came upon us somehow as a surprise, and even though we heard the news from China, nobody really expected that we were going to have distance teaching. The Czech Republic started to shut down public life by closing schools, restaurants, theatres, cinemas, sport clubs, etc., in the middle of March, very soon followed by the closure of the borders with neighbouring countries. That was the toughest experience for me during the general restrictions because I felt terribly locked in. It must have been like this during communism, was one of my first thoughts.

As I teach at three different universities (one full-time, at the other two as an external member) I could observe how differently they coped with the challenges COVID 19 presented (and still present) for the organisation in general as well as for the teachers and students in particular. The university where I am teaching fulltime was standardly prepared for online teaching, which means they offer Moodle and Microsoft Teams to support distance teaching and learning. One school was very poorly equipped and switching to online teaching was a great challenge for them: they had no communication platform that met the requirements of online teaching. This fact was very time-consuming for me as a teacher because I had to build my own infrastructure to communicate with the students and to provide them with study materials.

When I teach a seminar, we discuss the compulsory reading face-to-face and I can somehow check who is prepared or not. But in online-teaching through Moodle I felt the need to check all the texts and tasks the students sent to me and give everybody an individual feedback. So, my work flow was much heavier than during an ordinary semester. And this impression was also shared by the students. They told me that they had to work much more than usual. I personally do not think so, but during the pandemic they were forced to fulfil all the tasks and readings they would have had to do also during an ordinary semester, but thanks to the online lesson they were more under control.

Gabriele Kotsis: Shifting to virtual teaching and working from home caused an unexpected increase in workload. It is noticeable that online teaching requires different didactic methods and tools and having your office at home means that you tend to say yes to even more meetings and tasks because you have the feeling of so much time, no delay because of travel ;-)

Nicole Horáková: One last word about my students because the possibilities available for them also had great impact on my work. To be honest, I was really surprised how poorly equipped some of them are for studying online: Some of them do not own a computer or notebook ready for online meetings, the camera and/ 
or the microphone does not work, and those students living in smaller villages do not have a stable internet connection. For them, this way of studying was very challenging.

\section{Editors: The COVID-19 crisis has revealed even more that the gap between rich and poor and the digitally integrated and disintegrated. Deevia and Tamara, what was it like in South Africa?}

Tamara Shefer: The pandemic and the lock-down in particular had a powerful impact on my work. First, I need to contextualise my university a little bit and how the responses to the pandemic affected things in South Africa and my university in particular. The university I am located at, where I have worked for 26 years, is what is known as a historically Black university, reserved in apartheid racist segregation policies and practices for 'Coloured' communities. While the postapartheid democracy since 1994 has attempted to desegregate and transform higher education, many of these now known as HDIs (historically disadvantaged universities) remain disadvantaged by historical inequalities and how they play out in the present. My university, for example, while now including diverse students, not only those designated historically as Coloured, still includes a majority of very poor students who have had disadvantaged educational and social backgrounds and many who come from rural areas. While the universities have attempted to challenge historical inequalities and facilitate epistemological access for students, many of our students are still challenged by material and discursive inequalities that are played out in experiences of in/exclusion and un/belonging in our universities.

So, when the pandemic hit South Africa, and a highly restricted lockdown was instituted, our university was closed and many of our students were sent home, often to rural areas, often with very little internet access, and even those in urban contexts were working with connectivity and data challenges. The university did begin providing data and devices, but this took quite some time, and for those of us involved as lecturers and heads of departments, as in my own case, a lot of time and energy was centred around this administrative practical component simply trying to ensure that our students could participate in online forums for their courses.

Deevia Bhana: The global spread of the disease and news of its devastating effects, which began with concerns in Italy and then spread across the globe, did produce anxiety, and like others I was anticipating catastrophe for South Africa - which at first glance appeared depressive in light of living conditions, health inequalities, and poverty. So, emotionally, this fear was great, but as the months have passed the fear has proved to be misguided, and thankfully South Africa has been spared the experiences that we have seen in other developed contexts. 


\section{N ROZHOVOR / INTERVIEW}

My students, who are all Master's level and PhD researchers, have been dramatically affected, and delays in graduation are expected. New measures were put in place to circumvent face-to-face contact, although this has also proved to be ineffective at times as the target population lack access to digitalisation, and their research activities are therefore compromised. Also, the use of cell phones, Zoom, WhatsApp, while useful under the circumstances, miss important elements of face-to-face contact and research that are critical for qualitative research. I chaired a Webinar that raised these issues with respect to support for children and young people no longer in school. I was also tasked with raising the issue of sexuality and young people, and how parents can support healthy sexual development when young people are not permitted to see each other under lockdown.

\section{Editors: This leads directly to our next question. How did you become familiar with digital work tools? \\ Deevia Bhana: Since March 2020 I have had to find myself in Teams, Zoom,} and learn how to navigate it. I am astounded at how much I now can do virtually. I had no idea how possible this was. I think gender plays an important role in how I perceived online digital media, and age and generation gaps in relation to social media. I continue to have handicaps not only with digital work tools but with my laptop, and simple things like how to have a different word view are complicated for me.

Nicole Horáková: Maybe I have the advantage that I am very much a technophile and interested in computer-based teaching. Even before the pandemic, I always offered online-based materials and exercises to my students. I like trying out new methods of teaching and possibilities for communicating with students and for meeting their needs. Against this background, the COVID pandemic offered me a great opportunity to try something new and use different channels. Before the pandemic it was not really necessary and there was no time for me to intensively explore the possibilities that the new technologies offer, but now I was forced to do this. This was for me, somehow, a positive outcome.

Mark Gatto: I was already familiar with social networking platforms like MS Teams and a range of other video conferencing tools prior to full-time online working, so the move online was fairly comfortable for me from a skills perspective. I have followed a blended approach to technology to limit my screen time where possible, so I take hand-written notes that I later scan to online folders. I also prioritised social discourse and I engaged in frequent online chat forums using enterprise social network platforms and video calls.

Chia Longman: As a university professor, the switch to working at home was not a huge impediment to work, but having to do this while caring for and home- 
schooling children was a nightmare, as these tasks cannot be combined. During the complete lockdown, for me personally, with a 5- and 12-year-old at home, this led to incredible amounts of stress due to continuous interruptions while at the computer, etc. I was able to carry out the minimum tasks required for teaching and administration, but hardly any research or writing, which require uninterrupted blocks of time.

The switch to digital tools mainly involved going from live to online meetings; the technical switch was not too challenging, but the meetings do not take place in the same way, as there is a lack of the social and physical aspects that are required in human interaction. There is little non-verbal communication. I think the toll of social isolation is becoming heavier on both staff and students. There is also the lack of informal meetings with colleagues 'in the hallway', picking up on news at receptions, etc. I also wonder what impact this will have on decision-making. On the other hand, I experienced it as 'better than nothing'. For teaching, the switch to online Zoom teaching in the first semester has been challenging. I see it working for small groups, but it is much more difficult for larger ones. I teach a gender studies class at the MA level and we had a $40 \%$ increase in student registrations this year, which means I am lecturing to 160 students whom I have never met in person. Didactically, I am sure online teaching also offers many opportunities, but becoming proficient and making use of its full potential requires extra time and effort and ideally additional staff and support. This is not provided, and ultimately teaching as such is not valued that much in research-excellence oriented institutions.

Anne Wagner: The pandemic has entirely changed my way of working, as everything has moved to remote. As a faculty member in a school of social work, I have not yet been fully challenged to be conversant in technology, beyond the basics. This shift has required me to self-learn numerous institutional electronic platforms.

In order to better contextualise my situation, I should explain that I work in a small, primarily undergraduate university. Our technical infrastructure is quite limited and our tech support minimal. Our excellent tech staff was already stretched to the limit before the pandemic. Hence, accessing needed support has been quite challenging and involves considerable waiting, which slows down my productivity.

Chia Longman: There are benefits and negative effects, very much depending on your position and situation. Digitalisation obviously opens up possibilities, for instance, for more efficiency, for saving time, and for participating in a cheaper and more ecological way in events, conferences, etc., instead of travel, so it might lead to more inclusion. So many lectures and workshops are now online and available to a larger audience at the click of a mouse! On the other hand, I find there is a study- or workplace intrusion into the private space and an accompanying 


\section{N ROZHOVOR / INTERVIEW}

flexibility demand. With care and family obligations at home, this does not make work any easier, it might worsen it. For example, in my own position I would rather travel to a conference, having ample work and preparation time away from home, and also to network, etc., than do the work at home with children on my lap, not to mention trying to find the time and peace and quiet to participate in webinars at 17.00 PM, etc.

Similarly, teaching live or digitally has advantages and disadvantages depending on positionality, which is often gendered. But an intersectional analysis is required. For working students, distance education offers more flexibility, while for younger students it might lead to loneliness and a lack of motivation and interaction with peers, etc. Our courses this year are even obligatorily recorded and made available online, which, again, offers flexibility for some, but undermines the notion of a safe space to speak, besides taking away some of the dynamics of a live lecture.

Jeff Hearn: The digital tools themselves have generally been fine, and there have been a lot of online events, which have meant more contact with people whom I wouldn't have usually 'met'. However, I think it can sometimes be difficult to have delicate or potentially conflictual discussions online, for example, around racism. It can be hard to convey online that you think someone has poor judgement, or just doesn't know about certain things, even whilst they may, of course, be thinking the same about you.

Tamara Shefers: In terms of my own experience, it was also a huge shift and new learning. I am fortunate to live in a privileged space with access to the internet, but I also had to immediately upgrade my own internet system to accommodate the online activities of virtual meetings, etc. But what was more important was the extension of my own skills base for digital pedagogy and scholarship and negotiating the strangeness and alienation of online forums.

While we were fortunate in that our department has always used our online teaching and learning site and has been relatively creative with using new technologies and digital and other creative pedagogical practices, I personally still relied a lot on the face-toface engagements with students. It has taken a long time to shift, to learn how to do things like narrated Powerpoint and video technologies, and most importantly I still find it a challenge to open up possibilities for participation and engagement. While our systems are now working, I still find a Zoom class extraordinarily empty, lacking in the vitality that group engagement brings, and it is really difficult to have a productive dialogue. Meetings online still feel so clumsy and are so much longer, often delayed and interrupted by our weak internet connectivity in this country in general. Similarly, we emphasise embodiment and affect in our pedagogical practices, and these technologies seem to further reiterate and reproduce the disembodied intellect that our patriarchal and (post)colonial scholarship privileges. 
On the other hand, I value that I have become more skilled with respect to digital technologies and am also beginning to think more creatively about how we can interrupt the lack of dialogue and participation that they seem to emphasise, thus undermining our usual pedagogical intention to centre student agency and foreground student knowledge and work in ways that also engage art, creativity, embodiment, and affect.

Editors: Did you perceive positive aspects of the lockdown, online teaching, or other changes brought about by the pandemic?

Nicole Horáková: So, during the pandemic I developed my own working routine and, to be honest, I loved it - even when it was more time-consuming than the faceto-face meetings. My life became slower and I had much more time for other things in life like gardening, cooking, or reading a good book that does not relate to my work. In conclusion, I would say that I became more domestic, more focused on my own needs and those of my family members, and I enjoyed this extraordinary time. But my positive personal attitude towards this situation was mainly influenced by the circumstances I live in: I have my own room equipped as a home office, a stable connection to the internet, and my children are old enough to organise their days themselves. But I can imagine that families have had to face great challenges, especially those with younger school-kids, with less space for working and living, or with bad technical equipment. So, I am aware that my working experiences during the pandemic were really privileged.

Jeff Hearn: COVID has also meant getting fitter by walking regularly twice a day. We're very fortunate to live in the city but also next to open country and woods where walking is relaxed. My life has become more domestic than in the recent past, less rushed, with more regular contact with some friends and family members one of whom has an immunity problem, so we've had daily contact. Gender issues pervade the content of my work, and my own immediate domestic routine has changed in a positive way.

Editors: That sounds quite relaxed, but if you have care obligations for children or relatives outside of your academic work, you were probably not quite as balanced. For example, studies on the gendered division of work in the household show that COVID-19 has led to a re-traditionalisation of house- and care-work. Mothers in particular have been heavily doubleburdened. What are your experiences?

Chia Longman: The major affect was for me as it was for many parents, with the closure of day-care and schools during lockdown. This meant I had to combine working at home with caring for and home-schooling children, who received some 


\section{N ROZHOVOR / INTERVIEW}

online education, but needed continual assistance and attention. In Belgium, schools closed from mid-March - and depending on the schoolyear - my youngest (5) returned to preschool mid-June. The eldest, in the first year in secondary school, did not go to school again until September.

Gender-related issues involve children generally being more geared to wanting attention and care from their mothers or mothers providing this more. This means that the opportunities for work performance for many mothers and others with caring roles, which is also often gendered, and which might even involve keeping up social contacts with the family online, etc., have certainly diminished and, because of this, women are more negatively affected by the pandemic generally. This is welldocumented by now. Even with nurseries and schools re-opening, social reproductive work and responsibilities still remain very intense, such as the continued 'home' administration, management, and communication due to the continuous shifts in COVID regulations on hygiene, meals, mobility, extra-curricular activities, etc. Caregiving support by others such as grandparents might also have disappeared for many.

Mark Gatto: My way of working was significantly impacted at the start of the COVID19 pandemic when the lockdown measures were applied in the UK. This was because my child, who was - 13 months old at the time - was previously in the nursery during the week but was now at home full time. My wife is a doctor, so I was working from home and looking after my child at the same time. This affected my work as I was no longer able to work during my usual hours (9am to $5 \mathrm{pm}$ ). Instead, I was working early morning, during their mid-day nap, and then in the evenings after they ${ }^{1}$ went to sleep. I was working from home on a laptop and it took a while to get used to the permanence of home-working compared to my previous mixture of office-based interactions with colleagues.

I became aware of the disproportionate impact of the lockdown on working carers, especially, as in my situation, for those with highly dependent infants. In conversations (online chat and video calls) with a fellow post-graduate student, we shared our struggles with childcare and work and I also learned about the gendered impact of the lockdown on caregiving mothers. As a working parent, I believe my experiences differed, to some extent, from the majority of fathers in the UK as I had sole responsibility for my child for extended periods of time while also working on my PhD and as a research associate. I was not alone in this experience, but it taught me a lot about the daily challenges and barriers facing working mothers who typically bear the greatest burden when it comes to childcare. In this sense, the COVID-19 pandemic and lockdowns have given me far greater personal insights into the value

1 In order not to reveal the sex of the child, the plural is used. 
of the caregiving experience as a basis upon which all working parents can build empathy and trust.

Anne Wagner: In terms of gendered impacts, I am acutely aware of the additional burdens women are experiencing as a result of caring responsibilities. In the Canadian context, we still have not established a national childcare programme, which continues to disproportionately impact women. Another issue that I expect will emerge is related to posting one's lectures on public platforms. At my institution, we are being directed to post lectures on You Tube. Although we are able to set privacy restrictions, as I am not familiar with this platform, I have concerns about who will have access. As has been widely documented, women tend to be at increased risk of cyber harassment. I am concerned that women may be at increased risk for such harassment as we increasingly move our lectures into the public domain.

Gabriele Kotsis: I personally didn't experience any gender bias but learned from my friends that it was more difficult for women to handle home office because, at least in Austria, there is still the general opinion that a women being at home has to take most of the work in the house, taking care of the kids, etc.

Editors: Gabriele has just now referred to the gender regime in Austria, which is rather conservative. We are wondering what the gender regimes in the other countries are like and what kind of dynamics digitalisation might have there. How do you assess the current situation in your country with regard to unequal gender-specific work patterns and digitalisation?

Nicole Horáková: As I have mentioned above: digitalisation and its impact on work and on society in general is not a big research topic in the Czech Republic. Neither the economy nor society or politicians are somehow aware of the fundamental changes we will face. Even gender-related issues in terms of work are not really the subject of discussion. Overall, the attitude in Czech society is rather neoliberal in terms of economics, and conservative in terms of family politics. In the Czech Republic, we have the longest parental leave worldwide and - nomen est omen it is called 'parental holidays'; in $98 \%$ of cases it is taken by young women/mothers. It is paradoxical, but my female students really think they have the same starting point and opportunities in their career as their male colleagues. Statistically, women earn around $22 \%$ less than men, politics are made by men, domestic and care work is still mainly done by women. My female students do not see a structural problem in this, but, consistent with a neoliberal attitude, they are convinced that, if they really want it and if they are good enough, they have the same opportunities as men in Czech society. But they are not aware that to be good is not enough; they have to be better to get nearly the same chances as the male students. 
Jeff Hearn: My first reaction to this question is to link back to COVID-19. I live in Finland, and there has been a strong and important presence of a women-led coalition government, which has been very effective. There have been relatively fewer infections than in many countries. In the early days of COVID, the five leading women ministers were doing daily press conferences together - almost a unique series of events in international governmental politics. There have been stories of young girls playing 'press conferences'.

More generally, Finland has a high level of women's full-time employment, high education levels, strong presence of women in politics and the state, less so at the top level of business, a form of 'gender-neutral' gender equality politics, along with strong permeation of ICTs/digitalisation, and during COVID a high level of taking up remote/ distance working (April/May 2020, estimates of between $60 \%$ and $76 \%$, perhaps the highest in the EU, https://www.eurofound.europa.eu/data/covid-19/workingteleworking), especially in the capital region and the main cities. At least some form of information society 'exists' and has for some time, albeit unevenly by age, class, and region.

There are certainly strong, unequal gender-specific work patterns that accompany digitalisation, including in the ICT and related sectors themselves, in both educational and vocational routes, and in employment and workplaces. Susanna Bairoh, whose $\mathrm{PhD}$ on women and girls in ICT, engineering, and STEM in Finland I am supervising, has just published on this in the Finnish situation (Naukkarinen, Bairoh 2020). Another area of unequal gender-specific work patterns and digitalisation is what happens in high-intensity business companies, where digitalisation operates in a profound way throughout almost all their work. This digitalised working life is accompanied by professionalised presentations of self as the fit, healthy, able-bodied, heterosexual body, whilst the negative impacts of stressful work on well-being remain taboo to talk of at work.

There are many other relevant questions. An important one, in Finland and beyond, is the online manosphere, and how this feeds racist, misogynistic, and right-wing politics, even if in Finland the men-dominated right-wing party is no longer in government, as it was previously, before we had the current womenled government coalition, with its daily online press conferences of the five women ministerial leaders.

\section{Editorial: Austria, the Czech Republic, and Germany have relatively similar conservative gender regimes, whereas Finland represents one of the Scandinavian models for a rather modern gender regime. What is the situation in South Africa?}

Tamara Shefer: South Africa is a complex context in which racial and class inequalities 
mean that many people do not have easy access to efficient and accessible digitalisation, so the move to work and study that is increasingly virtual widens the gap between those who are privileged and in privileged occupations and the majority who work in service industries, informal markets, etc.

South Africa remains a patriarchal society where gender binaries are still normative and policed across communities, notwithstanding a very progressive constitution and legal framework. Thus, the current lockdown and working from home undoubtedly will impact on women more negatively than men since women are still carrying more responsibility for care, often in either single-parent or patriarchal households. The lack of a divide between work and home may further add to women's multiple loads and capacity to balance diverse demands, when they are already burdened with greater care and reproductive labour in households.

\section{Editors: Tamara, your observation that racial and class disadvantages overlap with patriarchy points to the need for research on intersectionality. Deevia, how do you see this for South Africa?}

Deevia Bhana: South Africa's attack on COVID-19 was welcomed and generated a different view of the ruling ANC party and President Ramaphosa, especially as the speedy lockdown and efforts to curtail the spread were hailed as political gains. However, as the months went by, three issues stand out: Police brutality in enforcing adherence to the rules, domestic violence and women's vulnerability, and corruption, the abuse of disaster funds for COVID-19. Police brutality was especially visible in the township low-income settings and this caused a huge strain for the country as police were charged with murder in some instances. The focus on the police is not new - this focus has always been negative and what COVID-19 did was to expose further the gaps in the policing services, the flagrant violation of law, and police entitlements. Mainly poor people were impacted by police brutality.

With regards to gender, violence in the home was highlighted, exacerbating the already dangerous position of women and girls in the country. The effects of lockdown on family life exposed the gendered and sexual inequalities already in place, and the inability of the state to protect women is both a reality and exacerbated under lockdown. Finally, the issue of corruption placed the country back in the days of the Gupta saga and state corruption. Amidst concerns about people's suffering, especially poor and unemployed people, as well as the fact that people were dying of the disease, the effects of corruption were poorly addressed and remain a sore issue in the country. Indeed, discussions about children and young people in the midst of COVID-19 remain.

Clearly, access to the digital world remains unequal. This means that a majority 


\section{М ROZHOVOR / INTERVIEW}

of poor Black and also older women do not access the digital world. Men then remain powerful in relation to the new work arrangements, and control and dominate what women can do and have access to in households. Where there are no men as providers in the household, as is the case in many South African families, poverty, infrastructure, and lack of access mean the reproduction of gender inequalities.

\section{Editors: Mark, in your research you also problematise the cultural gender binaries that contribute to the 'breadwinner' and the 'maternity penalty'. Some hope that digital technologies will overcome these gender differences. What are your views on the UK in this respect?}

Mark Gatto: The UK is a technologically enabled country, and many professional vocations are transferrable to online, home-working models. I can see a potential divide growing between people whose jobs can transfer to technology-enabled home-working, and people whose professions do not allow such working patterns. This disparity may unduly affect face-to-face professions, which are statistically primarily comprised of women in the UK, such as nursing home carers, cleaners, and hospitality staff. Of course, this will also affect male-dominated professions such as construction, but the UK culture was already skewed to favour men's work over women's, especially concerning childcare responsibilities and as shown in the gender pay gap data. We are hearing a clear divide in media discussions between the potential benefits of home-working for those who are fortunate enough to be able to access this type of working arrangement versus a section of society who may be left behind, this may be particularly damaging to working mothers. If working mothers, who were already disadvantaged in the marketplace, through having the majority of childcare responsibility, are further disadvantaged by not being able to access the benefits of home-working, it could cause further social divides according to the intersection of gender and socio-economic status.

My hope is that fathers who have been spending a greater proportion of their day on childcare may learn from their increased time doing childcare and continue to contribute more after the pandemic restrictions are lifted in the future. I hope that the digitalisation of work, which enables home-working, can be a catalyst for more involved fatherhood and a culture shift for working fathers through increased opportunities and normalised discourse on spending time with their children.

Chia Longman: It would depend on the type of work. Working at home is increasing now in Belgium; it provides options for less traffic, less wasted time commuting, lack of office space, etc. But it also means an intrusion on the private space, the potential dissolution of boundaries between work and private life, etc. Men might have become more involved in domestic work because of this, but I have not seen any research yet. In general, I think the outsourcing and sharing, 
beyond the couple, of certain forms of care are required for gender equality; and digitalisation, involving more working at home, for example, and digital home schooling, will not benefit this.

Mark Gatto: From my own experiences, I am more committed to being a primary caregiver to my child than I was before the lockdown. This is a direct consequence of the sustained time I spent with my child and the freedom that digitalised working patterns affords. I hope that other fathers may also see the benefits of their increased caregiving role as a consequence of the time gained from home-working, but I worry there will be a digital divide between those whose professions enable home-working and those who must continue to commute and work away from home and family.

Editors: We come to the last question, which is of particular interest to us as researchers: How is your field of research currently changing on the connection between work, gender, and digitalisation? What do you think are the major issues regarding this?

Nicole Horáková: Maybe I have to disappoint you with my answer, but so far the pandemic and the ongoing changes due to COVID-19 have had no impact on my current fields of research. The issue of work in general is not a very widespread topic in Czech academia; there are some researchers dealing with gender issues also in connection to work, but I cannot say that we have a strong research tradition on these topics. Even the discussion in society was not much influenced by the changes we experienced during the pandemic: full-time working mothers substituting school teachers, working from home, the blurring of the private and the working space, the impact of the upcoming and/or ongoing digitalisation do not rank among the main topics of sociological research in the Czech Republic. So, what I am interested in is kind of 'exotic' here. And the pandemic - with the different working routine - gave me the chance to apply for a grant to investigate the migration of coalminers and their self-image in the region where I live in the Czech Republic. This has nothing to do with digitalisation or other actual topics that sociologists in other countries are dealing with, but for the sociology of work in the Czech Republic, it could be a beginning.

Anne Wagner: As my research spans higher education as well as social work, digitalisation is having an enormous impact on my work. One aspect that is challenging involves reaching potential research participants. Many of the women who are the focus of some of my research are extremely marginalised and often living in poverty. Consequently, many do not have easy access to the internet, nor may they have adequate technology. The pandemic has vastly increased their marginalisation. 


\section{N ROZHOVOR / INTERVIEW}

Attempting to connect with potential research participants electronically is also challenging in terms of establishing rapport. It is much more challenging to establish a relationship remotely. As the women I am engaging all have histories of trauma, establishing rapport can be challenging even when face to face. Also, I think research participants may be difficult to recruit due to privacy concerns. Communicating remotely adds additional complexities that have yet to be fully revealed.

Chia Longman: For research, as an ethnographer, face-to-face research is difficult and the switch to digital research is possible, but with a different approach. Digitalisation requires a lot of energy; to interact constantly with other humans on a screen cannot supplant face-to-face interaction, although for sure certain types of meetings will be here to stay for more efficiency and possibly inclusion, I think. Personally, I aim to draw on the momentum of more distancing, fewer events, more solitude, etc., to concentrate on more writing, but that might be wishful thinking!

Gabriele Kotsis: I am currently working with a couple of PhD and Master's level students on scenarios for future meetings and conferences being characterised by hybrid collaboration, i.e. intersecting phases of synchronous/asynchronous and real/ virtual presence in a mix. We are currently trying to come up with models for those hybrid collaboration scenarios, and if the data allow, we would also be very interested in studying difference with regard to gender.

Tamara Shefer: Generally, the research my students do in the areas of work that I research is focused on narratives and experiences related to sexuality and gender in/ justices. The current context has meant that we have had to engage in digital research methods, which has been another learning curve. All our students engaging in research have been exploring ways of conducting qualitative research in contexts of distance WhatsApp, email interviews, etc. - and this has actually been quite productive. It has also been really special to be collaborating across global contexts - I have found people all over very generous and inclusive about sharing ideas and resources in this respect, and this has definitely been a positive outcome. I also think the data may be very interesting - that people can share in different ways through these different modalities. But it also really makes it difficult to think about doing relational and participatory research, which we foreground in our teaching of research when we are so disconnected. But new ways to make connection and facilitate relationally need to be sought.

My own research field has increasingly moved into a post-qualitative way of doing scholarship. I have been thinking with material from the outside world and what others have written, rather than gathering data, so there is now, of course, even more material to think about - also about what has been raised in this time about 
the areas of research I am working on. COVID-19 and our national and transnational responses to the virus have amplified existing global and local inequalities, particularly intersectional gendered inequalities and injustices, and there has been a lot of interesting scholarship that has raised key concerns in global and local contexts.

Jeff Hearn: I work across quite a few different areas and work, and gender and digitalisation affects all of them; the relations of work, gender, and digitalisation have been a major research preoccupation of mine since the late 1990s. Some important questions seem to include: the physical and social dispersion of work in relation to gender and digitalisation; uneven and changing (over time) gender effects of digitalisation on employment structures; gender structures of the ICT sector; the embedded pervasiveness of 'the transnational' and transnational socioeconomic processes, including ICTs, and not just for transnational workers or those who migrate, as many, perhaps most, workplaces are in some sense transnational, even if just through the use of IT systems, as well as complex transnational business trading and ownership patterns, not least in the field of care; the everyday impacts of both the positive and negative aspects of greater digitalisation - for example, social and political networking, image- and text-based online abuse and violation, and their effects on the world of work and employment; new forms, and sometimes problems, of cyber-management; the closer intertwining of work and home/family/household, which have had negative effects for some women; changing and non-local forms of power for men and masculinities online; and increasingly the blurring of the onand offline in hybrid forms of sociality.

More broadly, work, gender, and digitalisation operate in relation to further trans-societal processes; I've been reflecting on some of the implications of COVID in a blog that the Brazilian Sociological Association organised (https://blogbvps.files. wordpress.com/2020/05/jeff-hearn.pdf). Another key, and still neglected, angle is the interrelation of age, gender, work/organisations, and digitalisation. This has been very important in the book, Age at Work, that Wendy Parkin and I have just finished.

Deevia Bhana: I think that digital contact is important. It opens up new possibilities of connection and has a global impact as well. I have been able to hook into Zoom and webinars across the globe. But there are limits - the digital space also is limited. I lose focus - the human contact is missing; the debate is less rigorous, as is my concentration. I am unable to focus a full day on a Zoom meeting. Gender remains a key area of concern as women have to navigate work with digital demands, as noted above. 


\section{N ROZHOVOR / INTERVIEW}

Editors: At the end we would like to thank you! Thank you for sharing your ideas, experiences, and knowledge with us during these troubling times. Take care and stay healthy.

\section{References}

Naukkarinen, J., Bairoh, S. 2020. STEM: A Help or a Hinderance in Attracting More Girls to Engineering? Journal of Engineering Education 109 (2): 177-193, https://onlinelibrary. wiley.com/doi/full/10.1002/jee.20320.

(c) BY-NC Annette von Alemann, Julia Gruhlich, llona Horwath, Lena Weber, 2020.

(c) BY-NC Institute of Sociology of the Czech Academy of Sciences, 2020. 